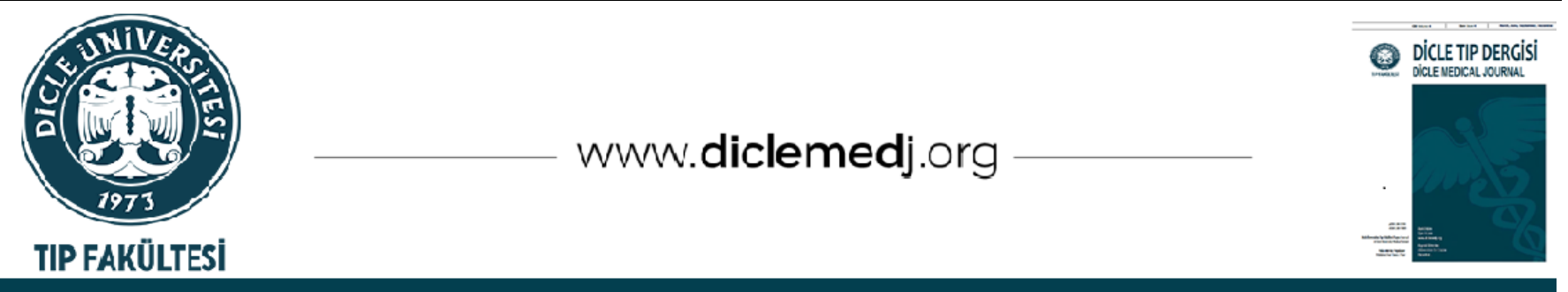

Özgüin Araştırma / Original Article

\title{
Pediatrik Pyoderma Gangrenozum
}

\author{
Rana Kapukaya $D_{1}$, Ahmet Kapukaya ${ }^{D_{2}}$, İsmail Akçay ${ }^{D_{2}}$ \\ 1 Sağllk Bilimleri Üniversitesi Adana Şehir Eğitim ve Araştırma Hastanesi, Plastik, Rekonstrüktif ve Estetik Cerrahi Servis Adana, Türkiye. \\ 2 Sağlık Bilimleri Üniversitesi Adana Şehir Eğitim ve Araştırma Hastanesi, Ortopedi ve Travmatoloji Servisi Adana, Türkiye \\ Geliș: 31.12.2020; Revizyon: 15.02.2021; Kabul Tarihi: 16.02.2021
}

Öz

Giriş: Sıklıkla erişkinlerde görülen Pyoderma Gangrenozum (PG)'un pediatrik hastalarda klinik prezentasyonu ve tedavisi ile ilgili farklılıkları göstermeyi amaçladık.

Yöntemler: Ekim 2018-Ekim 2020 yılları arasında hastanemize başvurmuş 8 PG hastasının klinik, histopatolojik ve tedavisi ile ilgili bilgilerini retrospektif olarak raporladık.

Bulgular: Hastaların ortalama yaşı 2.2 yıl (min 15 gün-max 9 yaş) idi. Cinsiyet dağılımı beşi kız, üçü erkek idi. Hastalarda lezyonlar daha çok gluteal bölge (7/8) yerleşimli idi. Gluteal ülsere sahip hastaların hepsi Suriye'li mültecilerden oluşmaktaydı. Hastaların çoğunda (7/8) sistemik steroid (1 mg/kg) ve topikal \%3 borik asit ile yapılan yara bakımında tam iyileşme sağlandı.

Tartışma: Daha önce yapılmış çalışmalarda çocuklarda görülen PG'un değişen anatomik bölge tutulumu gösterdiği ve inflamatuar barsak hastalığı ile birlikte sık görüldügü beyan edilmiş. Ancak bizim vaka serimizde ülserler sıklıkla gluteal, perianal ve perineal bölgede olup, bu hastalarda ilişkili başka bir hastalık bulunamadı.

Sonuç: Hastaların çoğunluğunun (7/8) Suriyeli mültecilerden olması, hastalığın demografik özellik gösterebileceğini ve etiyolojide çevresel ve genetik faktörlerin önemli olabileceğini düşündürmüştür. Pediatrik yaş grubunda görülen PG' un klinik prezantasyonu erişkin yaş grubundan farklı özellikler göstermektedir.

Anahtar kelimeler: pyoderma gangrenosum, pediatrik genital ülser, borik asit

DOI: $10.5798 /$ dicletip.887364

Correspondence / Yazışma Adresi: Rana Kapukaya, Sağlık Bilimleri Üniversitesi Adana Şehir Eğitim ve Araştırma Hastanesi, Plastik, Rekonstrüktif ve Estetik Cerrahi Servis Adana, Türkiye e-mail: dr_rana@hotmail.com 


\section{Pediatric Pyoderma Gangrenosum}

\section{Abstract}

Objective: Pyoderma Gangrenosum (PG) is commonly seen in adults. We aimed to show the differences in clinical presentation and treatment of $(\mathrm{PG})$ in pediatric patients.

Methods: In this study; we reported the clinicals, hystopathological and applied treatment informations of the patients who applied to our clinic with the pyoderma gangrenosum problem between the dates of October 2018 and October 2020 retrospectively.

Findings: The mean age of the patients was 2.2 years (min 15 days-max 9 years). The gender distribution was five girls and three boys. Lesions in the patients were mostly located in the gluteal region (7/8). All of the patients with gluteal ulcers were Syrian refugees. In most patients (7/8), complete recovery was achieved in wound care with systemic steroid (1 mg / kg) and topical \%3 boric acid.

Discussion: In previous studies, it has been stated that PG seen in children shows altered anatomical region involvement and is common with inflammatory bowel disease. However, in our case series, ulcers were frequently found in the gluteal, perianal and perineal regions, and no other associated disease was found in these patients.

Conclusion: The fact that the majority of the patients (7/8) are Syrian refugees suggests that the disease may show demographic characteristics and environmental and genetic factors may be important in the etiology. The clinical presentation of PG seen in the pediatric age group shows different characteristics from the adult age group.

Keywords: Pyoderma gangrenosum, pediatric, genital ulcers, boric acid.

\section{GíRiş}

Pyoderma gangrenozum (PG), farklı klinik prezentasyonlara sahip, nadir görülen bir nötrofilik dermatozdur. İmmün sistem disregülasyonuna bağlı başka hastalıklarla da birlikte görülebilir. Ülseratif kolit, Crohn hastalığı gibi enflamatuvar barsak hastalıklarına, lenfoproliferatif hastalıklara, vaskülit, immün yetmezlik, romatolojik hastalıklara eşlik edebildiği gibi PAPA (piyojenik artrit, PG ve akne) sendromu, Sweet sendromu (SS) gibi nötrofilik deri hastalıkları ile de ilişkili olarak görülebilir¹.

Etiyopatogenezde çevresel faktörlerin etkili olduğu iddia edilmekle birlikte, immun yetmezlik daha popüler bir teoridir ${ }^{2}$. Tanı kriterleri konusunda henüz fikir birliği yoktur. Klinik olarak ülserin özelliğine ve ayırıcı tanıların ekarte edilmesine dayanmaktadır. PG özgü patogonomik bulgu veya test yoktur.

Tanı koymadaki zorluk ve bu konudaki yapılmış epidemiyolojik çalışmaların oldukça sınırlı olması nedeni ile hastalığın insidansı ve prevelansı hakkında yorumda bulunmak güçtür. PG en sık erişkinlerde görülmektedir. Kadınların daha fazla etkilendiği bilinmektedir. Erişkinlerde görülen PG olgularının yarısından fazlasında ilişkili sistemik bir hastalık bulunmaktadır. Erişkinde paterji ve iliş̧ili hastalık sıklıkla bu hastalığa eșlik etmektedir³. Ancak pediatrik PG hakkında yeterli veri bulunmamaktadır.

Patogenezde immün cevap suçlandığ 1 için tedavinin temeli steroide dayanmaktadır. $\mathrm{Bu}$ tedavinin haricinde siklosporin, metotreksat, dapson, tümör nekrozis faktör (TNF) alfa inhibitörleri, sülfasalazin gibi ilaçlar da denenmiştir ${ }^{4}$.

Hastanemize başvuran sekiz pediatrik hastanın klinik verilerini, uygulanan tedavileri ve sonuçlarını güncel gelişmeler ışı̆̆ında tartışmayı ve $\mathrm{PG}^{\prime}$ un pediatrik yaş grubunda farklı anatomik tutulum gösterdiğini ve izole olarak görüldüğünü göstermeyi planladık. 


\section{YÖNTEMLER}

Kliniğimizde Ekim 2018 - Ekim 2020 yılları arasında Adana Şehir Eğitim ve Araştırma Hastanesi' ne başvuran ve pyoderma gangrenosum tanısı konulmuş sekiz pediatrik hasta çalışmaya dahil edildi. Hastalara tedavi oldukları plastik cerrahi ve ortopedi servis doktorlarınca telefonla ulaşıldı ve hastaneye çağrılarak, bilgilerinin kullanılabilmesi hususunda onamları alındı. Hastane işletmesinde ISO 9001 kalite yönetim sistemi uygulamaları uygulanmaktadır. Hastaların bilgi işlem sistemindeki kayıtları retrospektif olarak incelendi. Başvurup, tedavi oldukları dönemde yapılmış muayene bulguları, histopatolojik incelemeleri, tam kan sayımları, rutin biyokimya ve yara kültürleri, eşlik eden hastalıkları, ilgili bölüm konsültasyonları(dermatoloji,pediatri, immünoloji,patoloji,mikrobiyoloji) ve tedavi protokolleri detaylı olarak incelendi.

Histopatolojik incelemede insizyonel biyopsi sağlıklı cilt-lezyon sınırından alınmış olup numune hasta klinik bilgilerini içeren form ile birlikte, formaldehit içinde patolojik inceleme için labaratuvara gönderilmiştir.

Hastalara ait rutin labaratuvar tetkiklerinin yanısıra çalışılmış immün panel, yara kültür antibiyogram, kan çinko seviyesi, periferik yayma inceleme, vasküler renkli dopler inceleme, seroloji ve İFA sonuçları incelendi.

Hastalara ait 2 buçuk yıllık takip bilgisi mevcut olup, taburcu sonrası takibi ilgili branş tarafından yapilmıştır.

Etik Komite Onayı: Bu çalışmaya Tıp Fakültesi Eğitim ve Araştırma Hastanesi Klinik Araştırmalar Etik Kurulu onayı (68/110) alındıktan sonra başlanmıştır. Çalışma Helsinki beyannamesine uygun tamamlanmıştır. Hastalardan bilgilendirilmiş onam formu onayı alınmıştır.

Dahil edilme ve dișlama kriterleri: 18 yaşından büyük, klinik takipleri düzenli yapılmamış hastalar çalışmaya dahil edilmedi.18 yaşından küçük, PG tanısı almış, klinik takipleri düzenli yapılmış 8 hasta çalışmaya dahil edildi.

İstatistiksel analiz: Hastaların yaş ortalaması için aritmetik ortalama hesaplandı.

\section{BULGULAR}

2018-2020 yılları arasında kliniğimize başvuran PG tanısı konulmuş toplamda sekiz hastanın verilerini derledik. Hastaların yaşı ortalama 2,2 yıl ( min on beş gün- max dokuz yaş) idi Hastaların 5'i kız, 3'ü erkek idi.

Hastaların yedisinde lezyon gluteal bölgede, bir hastada bilateral alt ekstremitede idi (Resim 1 ve 2).

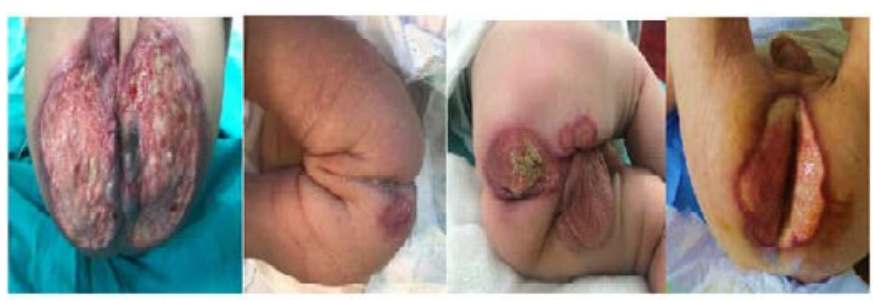

Resim 1: Gluteal,perineal ve perianal ülserli hastalarda ilk başvurudaki resimler

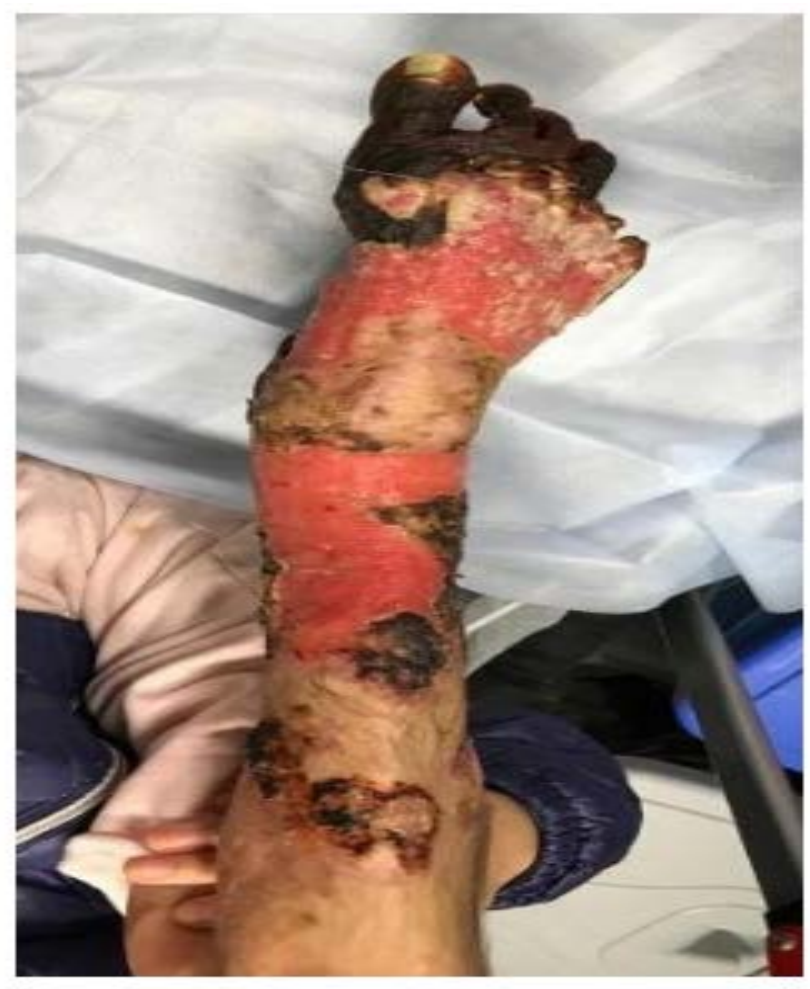

Resim 2: Alt ekstremitede ülser ile başvuran PG hastası

Hasta yakınlarından lezyonun küçük bir sivilce olarak başladığı, zamanla agresif bir şekilde büyüdüğü öğrenildi. Lezyonların etrafında ciltten kabarık mor bir halo izlendi. Ülser yüzeyi düzensiz olup, deride enflamasyona ait ödem, kızarıklık mevcut idi. Çocuk veya bebek hastalarda ağrının neden olduğu huzursuzluk tablosu izlendi. Bebek 
hastalarda tek kullanımlık alt bezi kullanılmakta idi. Hastaların ilk olarak dermatoloji polikliniklerine başvurduğu, antibiyotikli veya antifungal pomadların denendiği öğrenildi. Bu bilgiler dışında hasta yakınlarının geleneksel herhangi bir tedavi yöntemi uygulamadığı öğrenildi. Gluteal ülserlerin tek taraflı olarak başladığı, lezyonun büyüdükçe iki taraflı özellik kazandığı izlendi.

Tablo I: Hastalara ait klinik ve histopatolojik bulgular

\begin{tabular}{|c|c|c|c|c|c|c|c|}
\hline $\begin{array}{l}\text { Hasta } \\
\text { no }\end{array}$ & $\begin{array}{l}\text { Cinsi } \\
\text { yet }\end{array}$ & $\begin{array}{l}\text { Ya } \\
\text { ş }\end{array}$ & $\begin{array}{l}\text { Komorb } \\
\text { idite }\end{array}$ & $\begin{array}{l}\text { Ülser } \\
\text { lokaliza } \\
\text { syonu }\end{array}$ & $\begin{array}{l}\text { Cilt } \\
\text { bulg } \\
\text { ular } \\
1\end{array}$ & $\begin{array}{l}\text { Histopatol } \\
\text { oji }\end{array}$ & Tedavi \\
\hline 1 & $\mathrm{~K}$ & $\begin{array}{l}13 \\
5 \mathrm{~g}\end{array}$ & - & Gluteal & $\begin{array}{l}\text { Klas } \\
\text { ik } \\
\text { tip }\end{array}$ & $\begin{array}{l}\text { Dermal ve } \\
\text { subkutan } \\
\text { yağ doku } \\
\text { nötrofil } \\
\text { infiltrasyo } \\
\text { nu }\end{array}$ & $\begin{array}{l}1 \mathrm{mg} / \mathrm{kg} \\
\text { steroid } \\
\text { iv }\end{array}$ \\
\hline 2 & E & $\begin{array}{l}40 \\
\mathrm{~g}\end{array}$ & - & Gluteal & $\begin{array}{l}\text { Klas } \\
\text { ik } \\
\text { tip }\end{array}$ & $\begin{array}{l}\text { Perivaskül } \\
\text { er } \\
\text { mikroapsel } \\
\text { er ve } \\
\text { lenfositik } \\
\text { infiltrasyo } \\
\text { n }\end{array}$ & $\begin{array}{l}1 \mathrm{mg} / \mathrm{kg} \\
\text { steroid } \\
\text { iv }\end{array}$ \\
\hline 3 & $\mathrm{~K}$ & $\begin{array}{l}15 \\
\mathrm{~g}\end{array}$ & - & Gluteal & $\begin{array}{l}\text { Klas } \\
\text { ik } \\
\text { tip }\end{array}$ & \begin{tabular}{|l} 
nötrofil \\
infiltrasyo \\
nu
\end{tabular} & $\begin{array}{l}1 \mathrm{mg} / \mathrm{kg} \\
\text { steroid } \\
\text { iv }\end{array}$ \\
\hline 4 & $\mathrm{~K}$ & $9 y$ & $\begin{array}{l}\text { Artrit } \\
\text { Genital } \\
\text { ülser }\end{array}$ & \begin{tabular}{|l} 
Alt \\
ekstrem \\
ite
\end{tabular} & $\begin{array}{l}\text { Büll } \\
\text { öz } \\
\text { tip }\end{array}$ & $\begin{array}{l}\text { hemoraji } \\
\text { enfarkt, } \\
\text { nekroz ve } \\
\text { fibrozis }\end{array}$ & $\begin{array}{l}\begin{array}{l}\text { Pulse } \\
\text { steroid } \\
\text { Siklospo } \\
\text { rin } \\
\text { Inflixim } \\
\text { ab }\end{array} \\
\end{array}$ \\
\hline 5 & E & $\begin{array}{l}2,5 \\
y\end{array}$ & - & Gluteal & $\begin{array}{l}\text { Klas } \\
\text { ik } \\
\text { tip }\end{array}$ & \begin{tabular}{|l|} 
fibrinoid \\
nekroz \\
dermal kan \\
damarları
\end{tabular} & $\begin{array}{l}1 \mathrm{mg} / \mathrm{kg} \\
\text { steroid } \\
\text { iv }\end{array}$ \\
\hline 6 & $\mathrm{~K}$ & $\begin{array}{l}13 \\
\text { ay }\end{array}$ & - & Gluteal & $\begin{array}{l}\text { Klas } \\
\text { ik } \\
\text { tip }\end{array}$ & \begin{tabular}{|l} 
dermal \\
ödem ve \\
kronik \\
iltihap \\
hücreleri
\end{tabular} & $\begin{array}{l}1 \mathrm{mg} / \mathrm{kg} \\
\text { steroid } \\
\text { iv }\end{array}$ \\
\hline 7 & $E$ & $2 y$ & - & Gluteal & $\begin{array}{l}\text { Klas } \\
\text { ik } \\
\text { tip }\end{array}$ & $\begin{array}{l}\text { Dermal ve } \\
\text { subdermal } \\
\text { nötrofil } \\
\text { infiltrasyo } \\
\text { nu }\end{array}$ & $\begin{array}{l}1 \mathrm{mg} / \mathrm{kg} \\
\text { steroid } \\
\text { iv }\end{array}$ \\
\hline 8 & $\mathrm{~K}$ & $3 y$ & - & Gluteal & $\begin{array}{l}\text { Klas } \\
\text { ik } \\
\text { tip }\end{array}$ & $\begin{array}{l}\text { Dermal ve } \\
\text { Perivaskül } \\
\text { er, } \\
\text { lenfositik } \\
\text { infiltrasyo } \\
\text { n }\end{array}$ & $\begin{array}{l}1 \mathrm{mg} / \mathrm{kg} \\
\text { steroid } \\
\text { iv }\end{array}$ \\
\hline
\end{tabular}

K: Kadın, E:Erkek, g: gün, y: yıl,
Hastaların hepsine ilk başvurdukları zaman periyodunda insizyonel biyopsi yapılmış idi, histopatoloji raporlarına hasta bilgi sisteminden ulaşıldı. Ayırıcı tanıda, alt bezi kullanımına bağlı dermatit, arteryel ve venöz ülserler, bakteriyel ve mikobakteriyel enfeksiyonlar, fungal enfeksiyonlar, ektima gangrenosum, çinko eksikliğine bağlı akrodermatitis enteropatika, vaskülitler, langerhans hücreli histiyositoz, maligniteler düşünüldü. Hastalara tam kan, periferik yayma, immün panel, metabolik hastalıklara yönelik tarama , mikobakteri kültürü ve PCR çalışılarak ayırıcı tanılar ekarte edildi.

Hastalara topikal yara bakımı \%3 borik asit solüsyonu tatbik edilerek yapıldı. Asit borik uzun yıllardır yara bakımında kullanılan bir antiseptik solüsyondur. PG hastalarında yara bakımında tercih edilmesinin sebebi antibakteriyel, antifungal ve antiviral özelliklerinin yanı sıra açık yara ve mukozal yüzeylerde kullanımın güvenli olmasıdır. Ayrıca son yıllarda yapılan çalışmalarda açık yaralarda güçlü protektif etki gösterdiği kanıtlanmıştır ${ }^{5,6}$.

Gluteal ülseri olan yedi hastaya tedavi olarak sistemik $1 \mathrm{mg} / \mathrm{kg}$ steroid tedavisi ile birlikte topikal yara bakımı yapılarak tam iyileşme sağlandı (Resim 3).

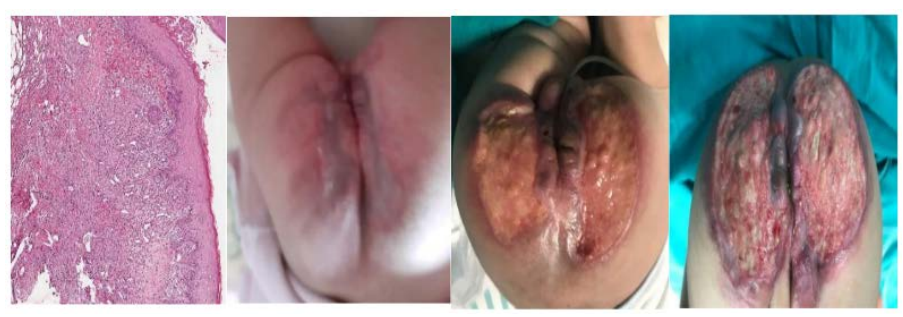

Resim 3: Sistemik prednizolon ve topikal \%3 borik asit solüsyonu ile iyileşme sağlanmış hastanın tedavi sirasinda resimleri

Bilateral geniş lezyonu olan hastaya pulse steroid tedavisin yanı sira siklosporin ve TNF alfa inhibitörü (infliximab) uygulanmıştır. Bu hastada bilateral metatarsal seviyede otoamputasyon gerçekleşti ve iyileşme sağlanamadı. 


\section{TARTIŞMA}

Pediatrik PG, nadir görülen ve birçok bilinmezi ve tartışmayı içinde barındıran ve henüz etiyolojisi tam olarak aydınlatılamamış bir dermatozdur. Bu hastalık hakkında en detaylı bilgiyi sunan, Kechichian ve arkadaşlarının ${ }^{7}$ yapmış olduğu metaanalitik bir çalışmadır. $\mathrm{Bu}$ araştırmada 132 makale incelenmiştir. $\mathrm{Bu}$ çalışmada olguların yarısından fazlasında PG hastalığına, eşlik eden başka bir hastalık tespit edilemedi. Hastalığın lokalize olduğu bölgenin değişkenlik gösterdiği ve uygulanan sistemik steroid tedavisinin ise \%90 hastada başarılı olduğu rapor edilmiştir.

Schoch ve $\operatorname{arkadaşları}^{8}$ tarafından yapılan ve rölatif geniş serili bir diğer çalışmada ise, pediatrik ülserlerin yetişkinlerden farklı anatomik dağılım gösterdiği, püstüler lezyonların daha baskın olduğu ve inflamatuar bağırsak hastalığı ile güçlü bir ilişkiye sahip olduğu bildirildi. Klinik seyrin, altta yatan sistemik hastalık ile korele olmadığı ve tedaviye yanıtın değişkenlik gösterdiği rapor edildi.

Bizim vaka serimizde de hastaların \%83'ünde ilişkili bir hastalık bulunamadı. Yukarda belirtilen araștırmadan farklı olarak, olgularımızda ülserlerin en sık yerleşim yeri gluteal bölge olarak tespit edildi. Diğer taraftan ülserasyonların iyileşmesine yönelik verilen sistemik steroid tedavisi ile yeterli başarı elde edilemedi. Bu tedaviye ek olarak \%üçlük topikal borik asit uygulandı ve tüm vakalarda iyileşmeye yardımcı olduğunu düşünmekteyiz. Vaka serimizde püstüler lezyon öyküsü sadece bir hastada $(\% 16,6)$ görüldü. Bu hastada ayrıca perineal ülser ve artrit ve paterji tespit edildi. $\mathrm{Bu}$ hastaya pulse sistemik steroid, Siklosporin, TNF alfa inhibitörü(Infliximab) tedavisi uygulandı. Ancak istenen cevap alınamadı. Yapılan angiografik çalışmada bilateral popliteal seviyeden itibaren, arterin distalinde total tromboz tespit edildi. Bu hastada distal phalankslarda otoamputasyon gelişti. Tedavi ile kür sağlanamadı. Bu hastamızın yaşı dokuz idi.
Hastalarımızın \%60'ı infantil yaş grubunda olup, bu hastalarda görülen lezyonların tamamı gluteal bölgede lokalize idi. Gluteal bölgede ülseri olan yedi hasta da yabancı uyruklu mültecilerden oluşmakta idi. Yaş ortalamaları daha önce bildirilen pediatrik yaş grubundan oldukça küçüktü.

Bizim olgularımızda bu hastalığın seyrinde bölgesel etmenlerin, sosyoekonomik seviyenin, çevresel ve genetik faktörlerin önemli olduğu kanaatine varılmıștır. Ek olarak infantil yaş grubunda oluşan bu ülserlerde, sistemik steroid ve \%3' lük borik asitle yapılan topikal uygulamalar yeterli bir tedavi gibi görünmektedir.

$\mathrm{Bu}$ hastalığın etiyolojisinde, çevresel ve sosyoekonomik faktörlerin de oldukça önemli olduğunu düşünmekteyiz. Ancak bu hastalığın oldukça nadir görülmesi ve ayrıca halen tanısal zorluklar içermesi kesin bilgilere ulaşılmayı engellemektedir. Bu nedenle bu hastalığın daha detaylı araştırılması için çok merkezli çalışmalara ihtiyaç vardır. Pediatrik yaş grubunda görülen $P G$, yetişkinlerde görülen hastalıktan farklı bulgular içermektedir. $\mathrm{Bu}$ hastalarda yara bakımı konusunda antiseptik ve protektif etkisi bulunan, açık yaralara tatbik edilebilen $\% 3$ borik asit solüsyonunu alternatif bir yöntem olarak önermekteyiz.

Her ne kadar genital, perineal ve perianal ülser görülen hastalarda birlikte başka hastalık görülmemiş olsa da yaşamın ilerleyen dekadlarında herhangi bi malignite veya immün sistem ilişkili hastalık olmayacağı anlamına gelmemektedir. Bu nedenle bu hastaların uzun süreli takip edilmeleri gerektiğini düşünmekteyiz. Çalışmanın en önemli limitasyonu retrospektif olmasıdır.

\section{SONUÇ}

Pediatrik yaş grubunda gluteal bölgede, etyolojisi anlaşılamayan, atipik ülser ile karşılaşıldığında mutlaka PG'un hatırlanması gerekir. Çünkü bu hastalar doku defekti veya 
malignensi olarak düşünülüp opere edilebilir. Oysa bu hastalarda cerrahi kontrendikedir ve bazı subtiplerinde paterji pozitiftir. Ayrıca cerrahi sonrası gelişebilen $P G$ ile de karıştırılmamalıdır.Bu hastalarda histopatoloji nötrofilik dermatoz ile uyumlu olup,insizyonel biyopsi tanı koymak için değil, ayırıcı tanıların ekartasyonu için yapılması gereklidir.

Etik Kurul Kararı: Bu çalışmaya Tıp Fakültesi Eğitim ve Araştırma Hastanesi Klinik Araştırmalar Etik Kurulu onayı (68/110) alındıktan sonra başlanmıştır. Çalışma Helsinki beyannamesine uygun tamamlanmıştır. Hastalardan bilgilendirilmiş onam formu onayı alınmıştır.

Çıkar Çatışması Beyanı: Yazarlar çıkar çatışması olmadığını bildirmişlerdir.

Finansal Destek: Bu çalışma her hangi bir fon tarafından desteklenmemiştir.

Declaration of Conflicting Interests: The authors declare that they have no conflict of interest.

Financial Disclosure: No financial support was received.

\section{KAYNAKLAR}

1. Bulur O, Karadağ AS, Nazlıgül Y, Güreşçi S. Crohn hastalığında piyoderma gangrenosum: Olgu sunumu ve literatürün gözden geçirilmesi. Dicle Med J. 37: 418-421
2. Alavi A, French LE, Davis MD, et al. Pyoderma Gangrenosum: An Update on Pathophysiology, Diagnosis and Treatment. Am J Clin Dermatol. 2017; 18: 355-372.

3. Pektaş SD, Özoğuz P. Current Overview of Pyoderma Gangrenosum. Journal of Clinical and Analytical Medicine. 2015; 1-7.

4. Braswell SF, Kostopoulos TC, Ortega-Loayza AG. Pathophysiology of pyoderma gangrenosum (PG): an updated review. J Am Acad Dermatol. 2015; 73: 691-8.

5. Tepedelen BE, Soya E, Korkmaz M. Boric Acid Reduces the Formation of DNA Double Strand Breaks and Accelerates Wound Healing Process. Biol Trace Elem Res. 2016; 174: 309-318.

6. Kapukaya A, Karaali E, Saler T, et al. The treatment of chronic wounds with polyurethane sponges combined with negative pressure wound treatment: a multi-center, prospective, randomized study. Med Sci Discovery. 2020: 7: 730-8

7. Kechichian E, Haber R, Mourad N, et al. Pediatric pyoderma gangrenosum: a systematic review and update. Int J Dermatol. 2017; 56: 486-495.

8. Schoch JJ, Tolkachjov SN, Cappel JA, Gibson LE, Davis DMR. Pediatric pyoderma gangrenosum: a retrospective review of clinical features, etiologic associations, and treatment. Pediatric dermatology, 2017; 34: 39-45. 